\title{
IS SINCERITY THE FIRST VIRTUE OF SOCIAL INSTITUTIONS? POLICE, UNIVERSITIES, AND FREE SPEECH
}

(Accepted 17 April 2019)

\begin{abstract}
In the final chapter of Speech Matters, Seana Shiffrin argues that institutions have especially stringent duties to protect speech freedoms. In this article, I develop a few lines of criticism. First, I question whether Shiffrin's framework of justified suspended contexts is appropriate for institutional settings. Second, I challenge the presumption that the knowledge-gathering function performed by police is necessarily compromised by insincere practices. Third, I criticize Shiffrin's characterization of the university as involving a complete repudiation of enforced consensus, and I express doubts about the close connection between education and democratic legitimation that Shiffrin endorses. Finally, I raise a problem with the book's overall argument: even if one agrees that speech freedoms are necessary for moral development, they also may be threatening to moral development. The upshot is that the protection of speech should be modulated in order to account for the potential conflicts between sincerity and other valuable ends, rather than being oriented above all to sincerity.
\end{abstract}

In Speech Matters, Seana Shiffrin forcefully argues that we are each under a moral imperative to nourish, sustain, and participate in practices of sincere truth-telling. ${ }^{1}$ This moral imperative arises from the significance of self-disclosure in enabling us to develop and flourish as moral agents. In the final chapter of the book, Shiffrin turns her attention to the duties of truth-telling in institutional contexts. The philosophical agenda of the chapter can be divided into two parts. In the first part, Shiffrin argues against any sort of 'institutional exceptionalism' that would permit a relaxation of the duties of sincerity and truth-telling that otherwise apply to individuals.

\footnotetext{
${ }^{1}$ Seana V. Shiffrin, Speech Matters: On Lying, Morality, and the Law (Princeton: Princeton University Press, 2014). All parenthetical page references are to Shiffrin.
} 
While she recognizes that there can be some contexts in which the expectation of truth-telling is justifiably suspended, she maintains that the valuable aims of institutions do not provide sufficient justification. In the second part of the chapter, Shiffrin advocates more stringent duties of truth-telling for some institutions in light of their ends. In particular, she argues, the police and universities have special duties not to curtail speech freedoms and not to engage in deception due to their epistemic aims and social-symbolic function. Supplementing her argument with careful analysis of U.S. law, Shiffrin powerfully defends an unusual array of institutional freespeech policies, such as virtually boundless academic freedom, a prohibition on police misrepresentation, and the abolition of psychological research that deceives subjects.

In what follows, I develop a few lines of criticism of Shiffrin's arguments. Broadly speaking, they all stem from a suspicion that some valuable aims of institutions will inevitably conflict with duties of sincerity. Whereas Shiffrin sees the institutional imperative of truth-telling as non-overridable, I suggest that it may be permissible - at least in some circumstances - to balance it against other worthy aims. I develop this idea by discussing the particular institutions that Shiffrin considers: police and universities. I provide some reason to doubt that the knowledge-gathering role played by these institutions is necessarily compromised by insincere practices, pressing Shiffrin to explain why the pursuit of knowledge requires full disclosure. The examination of these institutions is meant to illuminate what I consider to be a tension in the overall argumentative strategy of the book, which I explain at the end. In brief, even if one agrees that the protection of speech freedoms is necessary for moral development, it also may be threatening to moral development. Since this threat is especially visible in our political life, the institutional context presents us with stark examples of value conflicts, some of which remain unresolved by Shiffrin's penetrating analysis.

I begin with Shiffrin's argument that institutions are not exempt from the duties of sincerity that apply to individuals. She grants that the value of being able to self-disclose mental contents is not in play for corporate persons, but she insists that the duties of truth-telling still apply because institutions are composed of individuals and often have individuals as their audience (pp. 98-102, 183-185). To tackle 
the institutional context, then, she extends her method for determining when truth-telling duties can be relaxed in the interpersonal context (p. 186). The method requires us to first ask whether we can justify the creation of a 'suspended context', i.e., a context in which the normative presumption of sincerity is disabled. Shiffrin allows that some suspended contexts can be justified because 'communication is... central to the pursuit of other valuable goals, whose realization may be disserved through expectations and practices of unexceptional, sober, literal sincerity' (p. 186). Shiffrin nominates four valuable goals that insincere communication could serve: humor, imagination, privacy, and hospitality. Shiffrin accepts a softening of the truth-telling requirement in service of these goals, as long as we preserve 'substantial space for the presumption [of truthtelling] to operate as a default' (p. 188).

I want to raise several doubts about the adoption of this method. First, it is not clear why valuable institutional aims cannot rise to the level of justifying suspended contexts. Shiffrin seems inclined to deny this possibility in general: 'It is an insufficient justification for the generation of a suspended context that it is generated to further the pursuit of a good end' (p. 187). Shiffrin is willing to admit that good ends like hospitality and privacy may be disserved through expectations of sincerity (p. 186). So it seems at least possible for valuable aims of institutions to be disserved in a similar way. On the one hand, Shiffrin could categorically deny this, which would require defending the view that when it comes to institutions, adherence to a norm of sincerity has an overriding priority over all other possible good ends. On the other hand, if she does not categorically deny that the good ends of an institution can justify a suspended context, then we need to hear more about what would count as sufficient justification. $^{2}$

Shiffrin's reluctance to consider good ends sufficient appears motivated by a concern that suspended contexts can have spillover effects. She says, '[If they are to be justified, s] uspended contexts cannot work on the individuals within such institutions so as to compromise their habits, expectations, and the personal honest

\footnotetext{
${ }^{2}$ Shiffrin seems to hedge in some places, saying the aims 'may be insufficient' to justify a suspended context (p. 185). But elsewhere she is more strident: 'Truth-telling is an essential, nonnegotiable activity. We cannot pursue our other ends to such an extent that truth-telling stops being reflexive or agents often find themselves in reasonable and serious doubt about whether assertions are presented to be trusted' (p. 188).
} 
relationships that facilitate their effective participation in our culture of presumptive truthfulness' (p. 194). This proviso seems intuitive at first, but applying it is nearly impossible. For one thing, it is difficult to define and delimit a context such that its consequences can be isolated and assessed against a counterfactual scenario. Even if this difficulty were overcome, what does it mean to compromise effective participation? One possible interpretation is that any context in which participants frequently don't tell the truth inevitably compromises the participants, simply because its regularity creates habits of untruthfulness that can't be contained. But this interpretation seems inconsistent with finding humor and hospitality to be adequate justifications, as Shiffrin does. Presumably even those who frequently communicate insincerely, such as stage actors and hotel staff, are able to participate in the broader culture of truthfulness. So the proviso about spillover effects cannot be interpreted in terms of the frequency of insincere speech. But until it is clear how we could know that a given suspended context would undermine the default presumption of truth-telling, we lack a basis for concluding that it is unjustified for that reason. ${ }^{3}$

But there is a deeper problem. The 'suspended contexts' method does not address the full range of issues posed by the institutional context. Institutions might have valuable aims that justify the relaxing of truth-telling duties without justifying the creation of a suspended context - indeed, a suspended context might hinder the

\footnotetext{
${ }^{3}$ A further issue is that Shiffrin seems inclined to categorically dismiss private ends as a source of justification, as becomes evident in her discussion of the law pertaining to puffery, i.e., exaggerated advertising. Part of her argument against allowing puffery is that, even if the suspended context serves some people's interests, the interests are less weighty because they are private and commercial, as opposed to public and civic (p. 191). But one can question the relegation of market exchanges to the category of merely private. Advocates of the free market claim that it has a combined public-private aim, since a system in which voluntary transactions are largely free from government regulation advances the general welfare. Hence a free-market system can be said to serve public and private ends in the same way that a university does, as Shiffrin acknowledges (p. 200). But even if the interests in question are entirely private, it is unclear why Shiffrin thinks that the private nature of a commercial interest weakens it as a possible basis for justifying the suspension. After all, commercial interests are no more private than humor or hospitality, practices that often subvert important public values (e.g., aristocratic manners that mark and exclude outsiders). This reinforces the worry that spillover effects are invoked too readily. Buyers and sellers whose exchanges regularly involve puffery are not so different from stage actors, and many cultures have customs of insincere posturing that reinforce social bonds, such as price-haggling or 'playing the dozens'. See, for example, Elijah Wald, The Dozens: A History of Rap's Mama (New York: Oxford University Press, 2012). I presume that Shiffrin does not want to condemn such a range of untruthful practices just because the benefits they produce are private. So in the end, the opponents of regulating puffery can resist Shiffrin's conclusion that the interests advanced by a commercial practice are - insofar as they are private- unsuited to justifying a suspended context.
} 
valuable aims. Shiffrin's method for justifying institutional insincerity does not address this possibility. Consider an example. In 2016, The New York Times interviewed then-President Barack Obama on the subject of his economic legacy. Obama confessed that he faced a challenge of political communication: 'It was a delicate balance throughout 2009 and 2010 to be straight with the American people about the depths of the problem, how close we were to disaster, without scaring the heck out of them'. ${ }^{4}$ Financial panic on the part of ordinary citizens would have wrecked the economic recovery, and so Obama adjusted his message accordingly. Call this the 'ship in a storm' scenario: Sometimes the pilot of a large ship in a menacing storm cannot tell the whole truth to his crew without seriously jeopardizing their safety. When lives are at stake, and the members of a group urgently need to act in a coordinated and confident way, then the duty of truth-telling ought to be relaxed. ${ }^{5}$

This scenario can be extended to less urgent cases where strict truth-telling may come into conflict with the pursuit of valuable aims. Consider an athletic coach focused on winning the next match, a union leader focused on gaining concessions for workers, or a diplomat in charge of negotiating an end to armed conflict. Communication is modulated in order to best serve those goals, and there is a marked difference between what is owed to insiders versus outsiders. This demarcation could well serve the interests of outsiders - for instance, the deterrent effect of insincere threats has helped us avoid nuclear war (thus far). ${ }^{6}$ Even the everyday role morality of professionals may justify reducing the stringency of truth-telling. Suppose a doctor in a publicly funded health system is considering whether to prescribe an antibiotic to a patient, and the doctor is concerned about increasing antibiotic resistance in a population. Suppose that the balance of the doctor's duties clearly weighs against prescribing an antibiotic to this patient; the patient is

\footnotetext{
${ }^{4}$ Andrew Sorkin, 'President Obama Weighs His Economic Legacy'. The New York Times (2016, April 28).

${ }^{5}$ The classic example of a political leader speaking untruthfully out of necessity is the noble lie described in Plato's Republic. See Plato, Complete Works (Indianapolis: Hackett, 2005). There Socrates argues that myths have legitimate usefulness as a political remedy, though their use is limited to those in leadership positions and must serve the good of the city (Rep. 382, 389).

${ }^{6}$ The deterrence dynamic is dramatized in Shakespeare's Henry V. See William Shakespeare, Henry $V$, Simon and Schuster (2011). On a quest to retake land to which he believes he has a title, King Henry secures the peaceful submission of the French town Harfleur with a graphic depiction of his intention to raze it to the ground (III.iii.1-44).
} 
healthy and will make a full recovery, although it will take longer without the antibiotic. It seems that the doctor may permissibly communicate in a way that obscures the longer recovery time for the particular patient, in order to avoid suspicion that she may not be a competent doctor who cares about their health. ${ }^{7}$ Preserving the relationship of trust and confidence in the doctor is an important goal, one that would be disserved by literal truth-telling. ${ }^{8}$

These sorts of cases, in my view, display the limits of Shiffrin's emphasis on justifying a suspended context. For we may still wonder whether the duties of sincerity can be relaxed for certain valuable ends, ones that often rely on the preservation rather than suspension of a normal speech context. So, framing the question in this way removes our ability to see important instances in which misrepresentation in an institutional setting can be permissible, even though it isn't occurring in a justified suspended context.

To make these points more concrete, I want to consider one of the institutions that Shiffrin discusses: a police force. When it is functioning properly, a police force advances valuable aims such as peace and the reduction of fear. It is plausible to think that these aims are not always best served by literal truth-telling. But Shiffrin strongly disagrees, indicating that she regards the police - as well as universities, which I will come to shortly - as institutions whose particular ends and functions demand 'higher rather than lower fidelity to free speech and truth-telling' (p. 223). Her defense of this more stringent standard serves to highlight the limits of the suspended-context method.

Shiffrin claims that the police play a special role in 'our scheme of epistemic moral cooperation', one that is inconsistent with lying during interrogation (pp. 197-199). ${ }^{9}$ She describes the police as 'at all times engaged in educating citizens about the law', and she thinks that one of their compulsory ends is 'to act as a source of reliable and

\footnotetext{
${ }^{7}$ Shiffrin addresses role morality, but only to point out that the mere announcement that a context is suspended doesn't make it justified. She illustrates this by saying, 'The doctor cannot shrug off her duty to speak truthfully by declaring an intention to shirk it' (p. 192). This may be true, but it does not show that a valuable end is insufficient to relax the duty of truth-telling.

${ }^{8}$ Shiffrin would likely say that the doctor should divulge that she is not acting purely in the best interest of the patient, and then explain to the patient the justice of prioritizing the health of a population over an individual, or educate the patient on how his individual interests are bound up with the whole. But this sort of civic education of individual patients is unrealistic in a clinical context because of the very nature of the institution-and this is precisely the point.

${ }^{9}$ Her examples are appalling, e.g., an officer trying to induce a rape confession by telling a suspect that the officer had done something like that himself once. However, the impropriety of this behavior does not need to be diagnosed in terms of the special role of police as epistemic moral authorities.
} 
trustworthy moral knowledge about the law' (p. 199). Shiffrin thus regards the police as epistemic and moral authorities (pp. 198-199). She claims that there is such a tight link between their investigatory and educative aims that the police cannot argue that the mere significance of the end [of investigation] justifies the suspension of the truthfulness presumption' (p. 198). But as she notes later, the success of lying during interrogation depends upon the untruthful statement's being presented and perceived as truthful (p. 199). This observation should prompt us to examine whether valuable aims might justify police insincerity outside of a suspended context.

Regardless of the speech context, Shiffrin's view is that police lying is impermissible because the police 'subvert their own role when they misrepresent...' (p. 198). Why think this? Shiffrin claims that 'for the police, collecting and offering knowledge are necessarily intertwined' (p. 198). Particular episodes of gathering information do not require truth-telling, so I assume that Shiffrin thinks the connection lies at the level of practice (p. 199). But this connection is not necessary, since some deceptive police practices have been effective at gathering information over time (e.g., discreet surveillance). Shiffrin indicates that these practices will hinder effectiveness in the long run because they reduce 'justified credibility' (p. 199). But even if credibility is reduced, it cannot be assumed that a loss on this dimension would necessarily undo or outweigh the other gains that are achieved.

In denying that misrepresentation can ever be appropriate for police, Shiffrin assigns non-negotiable primacy to the educative role of the police, whereas it is more natural to consider it a subsidiary function. The role of the police (insofar as they are a functional public agency), is to aid in law enforcement by investigating crime and apprehending criminals. The education of citizens through exchanging information with police is subsidiary and instrumental to the investigation and prevention of crime. Even if one thinks that the aims of enforcement and education are on par, this would imply that they ought to be balanced whenever they cannot be reconciled. Instead, Shiffrin depicts the police as first and foremost public educators, such that conveying truths about the law is an overriding and primary aim of the job. 
Shiffrin's take on police lying underlines how preeminent she thinks the duties of truth-telling are, regardless of the other good ends an institution is pursuing. Surely if this is true anywhere, it would be in the case of a university. Nevertheless, I am not convinced that Shiffrin's account adequately grapples with the inevitable conflict between duties of sincerity and other valuable aims that universities have. Shiffrin invites the reader to regard a university as:

... a special sort of collaborative epistemic repository for humanity, a repository that aims to generate, cultivate, appreciate, disseminate, and preserve our best, sincere understandings of the domains of important human knowledge and the means, methods, and history of collecting them, both for the sake of knowledge and for many consequent purposes, long- and short-term. (p. 200)

This definition is appealing, but it immediately presents a tension between the activity of inquiry and the acquisition of knowledge. It should not be assumed that inquiry produces knowledge - after all, the only thing that Socratic cross-examination can demonstrate is ignorance. $^{10} \mathrm{~A}$ proponent of liberal education might prioritize inquiry, viewing the university as a place that nurtures individual development through self-liberation and self-realization. This developmental outlook may be in tension with speech freedoms, since it may call for restrictions on speech in order to provide a suitable environment for engaging in inquiry and dialogue.

In fact, Shiffrin acknowledges that a developmental outlook can justify speech restrictions in pre-college educational contexts. She says, '[Children's] early developmental stage may justify their subjection to rather comprehensive forms of compelled education, which include structured speech activities involving prolonged bouts of compelled listening and solicited speech' (p. 105). But an analogous case can be made at the university level. Professors sometimes reasonably expect students to expose themselves to points of view that they find abhorrent, for the sake of their moral and intellectual development. ${ }^{11}$ Some university classes involve structured debating assignments, such as being required to orally present arguments on both sides of a controversial issue. If Shiffrin is willing to permit

\footnotetext{
${ }^{10}$ Gregory Vlastos, 'The Socratic Elenchus'. The Journal of Philosophy 79(11) (1982): pp. 711-714.

${ }^{11}$ I don't mean to imply that exposure is itself morally neutral, or that the case for exposing students to ideas that make them uncomfortable must arise from purely civic or political considerations. In my view, that case must ultimately rest on a judgment about what is good for individuals. Judgments in this category are highly contextual and rightly belong to instructors, who are best placed to make them on the basis of their pedagogical and professional expertise.
} 
these sorts of compelled activities in schools on developmental grounds, then it is odd to rule out these grounds at a university. Shiffrin falls back on the 'special commitments the university makes to reject the presupposition of a univocal perspective...' (p. 213). But it is not clear why these commitments are special, since surely some schools also make them. If the commitments are occasionally overridable in schools, then in principle they are overridable in universities. $^{12}$

From her knowledge-based concept of a university, Shiffrin derives two imperatives related to governance: A university must oppose hierarchy, and it must oppose forced consensus. ${ }^{13}$ While these sound appealing, I am not fully persuaded by the defense of them as absolute imperatives. For one thing, it is not evident that universities by nature repudiate any form of enforced consensus. Institutional identity - that is, what makes it no more and no less than one body requires some shared recognition of norms of permissible behavior, including norms for identifying and sanctioning illicit behavior. ${ }^{14}$ If that shared understanding is to guide and shape how the institution conducts itself, there must be some form of discipline, maintained by the enforcement of institutional judgments (e.g., penalties for academic fraud, censure for neglect of teaching obligations, etc.). ${ }^{15}$

Shiffrin's presentation of these imperatives as absolute gives rise to a few difficulties. Consider her discussion of the way in which university decision-making will inevitably reflect corporate value judgments:

\footnotetext{
${ }^{12}$ In fact, universities allow for a finer-tuned balance of development and freedom than schools do, though it is still a balance rather than a full reconciliation. For example, the Columbia University philosopher Michele Moody-Adams explains that she requires students to read about but not write essays on topics that they find deeply troubling. Ethan Herenstein, 'Politics, Activism, \& the Modern College Campus: An Interview with Professor Michele Moody-Adams'. The Current (2016). Retrieved from http://www.columbia-current.org/moody-adams-interview-by-ethan-herenstein.html.

${ }^{13}$ Here one might think the distinction between a public and private university becomes significant, because private voluntary associations are permitted to enforce some basic consensus about the aims of the institution. Shiffrin limits herself to public universities, and she alludes to having an implicitly critical stance' towards private universities that 'promote particular viewpoints' (p. 200).

${ }^{14}$ For a defense of this ontology of institutions, see John Searle, 'What is an institution?' Journal of Institutional Economics 1(01) (2005): pp. 1-22. For an alternative ontology which also supports my point, see Frank Hindriks and Francesco Guala, 'Institutions, Rules, and Equilibria: A Unified Theory'. Journal of Institutional Economics 11(3) (2015): pp. 459-480.

${ }^{15}$ Shiffrin cannot fall back on a distinction between expression related to academic endeavors and expression related to matters of governance, as she observes later that this distinction is 'contestable' (p. 206).
} 


\begin{abstract}
$[\mathrm{M}]$ embers must make decisions, both individually and for the institution, about what topics are worth pursuing, what scholarship is qualitatively excellent and worthwhile, and which people and what institutional structures contribute well to [a flourishing] community. These judgments must themselves be independent and sincere, or else the institution will risk instituting a form of pre-ordained coordination about ideas indirectly through the selection of its members... These judgments should not be deployed whenever conceivable, but only to facilitate the construction and continuation of [a flourishing community]... Judgments allocating structures of power and establishing substantive priorities that determine the conditions of pursuing and disseminating knowledge ... should be understood, on principle, to be only provisional, periodically up for questioning and reconsideration. (pp. 201-202).
\end{abstract}

Shiffrin acknowledges that corporate judgments about what research is worth undertaking can effectively function to enforce consensus, and so this risk should be countered wherever possible by treating the decisions as provisional. ${ }^{16}$ But this recognition is in tension with Shiffrin's insistence that tenure is not problematic. She says, 'An appointment's permanence is designed not to reify a particular qualitative judgment, therefore, but to safeguard individual sincerity' (p. 202). In an institution governed corporately like a university, selection (and rejection) of members has just the sort of permanence that she worries about. Whether or not it is by design, the permanence functions to entrench the views of members on the qualifications for membership - including judgments about what sort of research is worthwhile.

Because particular viewpoints can come to predominate through the institution's governance structures of hiring and promotion, even governance norms that seem merely procedural can enable the indirect enforcement of consensus. Insofar as universities operate this way (and most do), they cannot entirely avoid some de facto enforcement of consensus about worthwhile research. In light of this, perhaps Shiffrin could qualify her proposed governance imperative to make it less absolute: 'Avoid enforced consensus unless it sets back the essential (valuable) aims of a university'. But this is precisely the maxim affirmed by her opponents, who use it to defend less-robust speech protections. Something similar can be said about her defense of the absolute imperative to oppose hierarchy. Even the most problematic university hierarchies bear some plausible connection to the aims of the organization. In the end, it seems that both the consensus and hierarchy imperatives must be qualified in

\footnotetext{
${ }^{16}$ Some institutional decisions are virtually impossible to reconsider later even if they were vigorously resisted at the time, such as starting a controversial degree program (e.g. engineering at the University of Chicago, business at the University of Oxford).
} 
some circumstances, and this casts doubt on Shiffrin's presentation of the imperatives as absolute.

Shiffrin is clearly right to say that a healthy university culture requires that academics not be unduly punished for expressing their opinions, whether on intellectual or organizational matters (p. 206). ${ }^{17}$ While I agree with the conclusion, I am unpersuaded by the rationale Shiffrin proposes. She hopes to justify this requirement by tying it to a particular view about democratic legitimation - one that assumes that free and open disagreement will ultimately be productive (pp. 208-210). I will call this credo 'democratic romanticism', as it envisions a society in which citizens work out their political disagreements while continuing to treat each other as free and equal. In this idealized vision, democratic deliberation embodies the only morally acceptable procedure for addressing and resolving intractable disagreement, thereby arriving at legitimate political decisions. ${ }^{18}$

This view of disagreement is overly romantic because it downplays the fact that some disagreement is gravely disruptive and does irreparable damage, both to individuals and to the quality of deliberation. In taking this view, Shiffrin stands in a long line of democratic theorists who construe public airing of opinions as a uniquely respectful and productive way of processing conflict and disagreement. This construal implies that collateral damage gets redeemed by its necessity as a part of the only decent form of popular selfgovernment. ${ }^{19}$ This ideal is considerably less appealing in a world where vicious cyber-bullies exploit the platforms that enable public reasoning, using them to harass individuals and punish the expression of certain political viewpoints. ${ }^{20}$

\footnotetext{
${ }^{17}$ I say 'unduly' to allow for instances of libel, privacy violation, etc.

${ }^{18}$ The tacit but necessary presumption of this view is that political decision-making fails by some standard internal to the nature of the activity if it isn't open, free, and inclusive, but this presumption is extremely difficult to defend independent of democratic starting points, such as political equality. See Thomas Christiano, The Constitution of Equality: Democratic Authority and Its Limits. (Oxford: Oxford University Press, 2008) and Joshua Cohen, 'Deliberation and Democratic Legitimacy', in Deliberative Democracy, eds. James Bohman and William Rehg (Cambridge, MA: MIT Press, 1997) pp. 67-91.

${ }^{19}$ For further critique of an approach that seeks to ground permissive speech freedoms in the normative requirements of democratic legitimation, see Amanda R. Greene and Robert M. Simpson, 'Tolerating Hate in the Name of Democracy', Modern Law Review 80 (2017) pp. 746-765.

${ }^{20}$ While bullies predate the internet, online platforms have made this threat particularly salient. For a recent example, see Rosa Brooks, 'And Then the Breitbart Lynch Mob Came for Me'. Foreign Policy (2017). Retrieved from https:// foreignpolicy.com/2017/02/06/and-then-the-breitbart-lynch-mob-camefor-me-bannon-trolls-trump/.
} 
Even if someone affirms this ideal view of disagreement for democratic government, it is still not clear why there must be a connection between the speech freedoms in a democracy and the speech freedoms in a university. In fact, something like democratic romanticism seems to operate in the background of Shiffrin's views of both. In her discussion of state censorship earlier in the book, she says that legitimate state action is meant to represent the collective expression of 'an inclusive association of independent minds' ( $p$. $110) .^{21}$ In the chapter on institutions, she speaks of an analogous process of democratic legitimation in the university, implying that the classroom is like a miniature society (pp. 212-213). But the university and its classrooms have particular aims - for instance, inquiry and development - that can come into conflict with the free airing of opinions. Only a democratic romanticist could deny this tension.

Furthermore, it is not clear that a university stands in need of public legitimation in precisely the same way that the state does, so the collateral damage cannot be redeemed so neatly in terms of its necessary role in the only available route to institutional legitimation. Another route to institutional legitimation might allow for a restriction on the speech of employees whenever it is egregiously disruptive to institutional functioning. But Shiffrin rejects this move, saying that 'the decision as to what counts as disruptive or inadequate work performance should be influenced and constrained by our free speech commitments' (p. 207). ${ }^{22}$ Such a strategy relies, again, on the preeminence of the requirements of institutional legitimation, as Shiffrin sees it. In the end, Shiffrin's arguments about the university derive from modeling its institutional legitimacy on an

\footnotetext{
${ }^{21}$ A subsequent sentence contains a gloss: '.. the fair functioning, the value, and the legitimacy of public democratic action presuppose that community members have (and regularly exercise) the ability to develop as full thinkers and then contribute their sincere and independently formed perspectives to the process of collective decision-making' (p. 110).

${ }^{22}$ She explains, 'The mere fact of doubts or dissension, along with the associated effects of reactions to them as such... cannot be treated as relevantly disruptive, 'efficiency-reducing', or incompetent to a discipline-worthy degree if, at the same time, we embrace freedom of speech and the more democratic criteria of success just articulated. In a free speech culture, part of management's task is to channel difficult outbursts or dissident expression so that, while they may naturally produce choppy waters, they do not mature into an unmanageable storm that disables colleagues from adequate job performance' (p. 208). I agree with Shiffrin that the adoption of such a criterion in Garcetti has led to decisions about police whistleblowing that are strained and implausible (p. 209). But I would not agree if the implication is that we should establish a different legal standard of disruptiveness. In my view, any such standard would invite exploitation by employers and governments, a risk that outweighs its potential to help us strike the right balance in particular cases.
} 
ideal theory of democratic legitimation (p. 213). Given how much work is done by this romantic view of democracy, it seems worthy of a more thorough defense.

Moving on to the research activities of a university, Shiffrin advocates a strict prohibition on misrepresentation in academic research. She argues that psychological researchers should not lie to subjects in order to learn about their behavior in particular circumstances. As in the case of the police, Shiffrin argues that misrepresentation would be self-undermining. But here the claim might seem more plausible, since the university's epistemic aim cannot be seen as instrumental or subsidiary - it is its raison d'etre. According to Shiffrin, the rationalization of academic lying in terms of salutary consequences is in tension with 'a posture of openness', and this posture is essential to 'ensuring the possibility of discovering and confirming truth' (p. 217). But again, the basis for this implicit claim of necessity is not clear. In fact, the claim is false insofar as we have empirical evidence that psychologists who employ insincere speech thereby discover and confirm truths about human behavior. Shiffrin remains adamant 'that the willingness to misrepresent facts, purposes, and aims in the service of obtaining and verifying knowledge calls into question virtually every representation of the academic' (p. 219). But we lack evidence that psychologists whose experiments involve misrepresentation are somehow less rigorous in their production of knowledge than other psychologists. ${ }^{23}$

Since the self-undermining claim looks so sweeping, it would help to clarify its scope by clarifying its basis. It is not clear whether the critical factor that categorically rules out misrepresentation is (i) that the institution is public, (ii) that it occupies a position of authority, or (iii) that its epistemic aims are overriding and non-instrumental. Distinguishing these three factors matters in order to see what work they each do in the argument. For instance, it would be implausible to say that psychological research conducted outside a university, by a private agency aiming at knowledge about behavior (e.g., market research), would be self-undermining if it engaged in deceptive research techniques. Market research is a large and successful industry,

\footnotetext{
${ }^{23}$ In footnote 54, Shiffrin cites a study finding that 'nearly 1 in 10 research psychologists has introduced false data into the scientific record' (p. 219). However, we lack information about whether that behavior is correlated with, much less caused by, administering experiments that involve deception of subjects.
} 
and it is hard to deny that it acquires and sells knowledge about human behavior. Even governments and NGOs find the market research industry's services valuable when they seek to advance socially valuable goals through behavior-change communication. These agencies may seek knowledge about what advertisements will effectively counter smoking, reduce unwanted pregnancies, or make people feel economically secure enough that they don't turn on their immigrant neighbors. If misrepresentation is the only way to gain this knowledge, and it is for a valuable aim that corresponds to pressing public interests, then the duties of truth-telling to research subjects ought to be relaxed. And to transpose this point back onto the police discussion, would there be anything wrong with the government hiring a private security agency to engage in deceptive interrogation, if it led to useful knowledge? Shiffrin's emphasis on the epistemic aspect of institutions like the police and the university reveals an unduly moralized picture of how institutions gain knowledge. This moralized account of knowledge acquisition is questionable in theory, but also in practical terms. If deceptive interrogation were to be prohibited, many people might suffer severe harms (e.g., potential victims of crime). This observation connects to my overarching question, which is why a valuable goal, when its pursuit by an institution requires insincerity, cannot be sufficient to relax the truth-telling requirement in some circumstances.

Shiffrin admits that complying with strict truth-telling norms is costly for institutions. She says, 'Institutional symbols... have importance because they are not empty or cheap. They operationalize devotion to a value and underscore how precious that value is, despite the obstacles and costs associated with its achievement' (p. 222). This social-symbolic argument both concedes that there are serious costs and insists that the costs can never be allowed to tip the scales, because institutions like police and universities should be moral 'beacons' for the rest of society. But by this logic, it would also be inspiring if universities - and corporations for that matter - engaged in global philanthropy, because the fact that they incurred substantial costs would make it all the more inspiring. No matter how inspiring some institutional behavior could be as an exemplar, it should count as a strict requirement only insofar as it pertains to the 
essential mission of the institution. Ultimately, the weight of this social-symbolic argument depends on first showing that exceptionless truth-telling is essential to the mission.

I close by posing a question that underlies the critique that I have been pursuing. As I see it, the basic thesis of the book is that robust speech freedoms are a necessary condition for our moral agency, and as such, they ought to be legally protected (pp. 86-87, 88-91). While it is evidently true that speech freedoms are necessary, it's also evident that they can confound our moral agency - for the simple reason that legal protection will end up covering speech that impedes moral development. To offer a mundane analogy: While it is necessary for us to ingest sugar in order to be healthy, undisciplined ingestion can confound or undermine our health. To put it abstractly, some activity $\mathrm{X}$ can be both necessary for some valuable goal $\mathrm{Y}$ and yet threatening to $\mathrm{Y}$, because $\mathrm{X}$ can both enable and impede Y. However, when considering a scheme of legal rights to X, the question becomes not only how important $\mathrm{X}$ is for $\mathrm{Y}$, but whether we can modulate the scheme of permissions to $X$ so that it sufficiently enables $\mathrm{Y}$ without confounding Y.

As far as I can see, Shiffrin's response to this difficulty is to include a proviso: Speech freedoms must be exercised responsibly, such that any threat to moral development can be effectively contained. She often places substantive conditions on what expression is to be protected, e.g., '[university members] should be insulated from suffering negative employment (and educational) repercussions as a response merely to the fact and content of the expression of their candid, responsible, supported, sincere opinions' (p. 213 fn 42). Her position seems to be that people deserve to have wide-ranging legal protection to engage in activity $\mathrm{X}$, provided that they will engage in $\mathrm{X}$ responsibly.

When we characterize the activity that is being legally protected as by-and-large responsible conduct, it is much easier to argue that it ought not be abridged for any other valuable ends. In that case, the contours of the legal protection would hug the boundaries of responsible exercise, like a licensing scheme. As in the case of other activities that we protect through licensing (such as driving), the scheme of permissions is modulated to balance the benefits of engaging in the activity with the risks of harm to others, and the 
permissions can be curtailed upon evidence of irresponsible behavior. But now we seem to have abandoned one important motivation for legally protecting speech: To liberate the thinker to speak their mind freely, which is one of the constitutive aspects of developing their individual moral agency as well as that of others. Thus, if speech freedoms are to fulfill their constitutive moral role, they must provide the individual with some relief from the endless burden of assessing whether her speech might lead to negative consequences. In this sense, speech's claim to be a protected activity is only tenuously related to whether it is exercised responsibly - legally protecting speech is less like a license and more like a right.

However, it appears that Shiffrin's account tacitly conditionalizes the legal protection of speech on an expectation of responsible exercise. As noted above, she seems to deny that institutional aims can be served by insincerity or disserved by sincerity. This sweeping denial suggests that truth-telling's negative consequences have been suitably metabolized by Shiffrin's latent proviso of responsible exercise. Nevertheless, speech freedoms often are not exercised responsibly, and in institutional settings the consequences can be grave. Insofar as Shiffrin's account relies on this proviso, it sidesteps this difficult issue.

In light of this unresolved tension, one might be tempted to think that there is nothing special that we can learn from the institutional context about the relationship between speech freedoms and moral agency. But I have argued that some morally valuable ends - ones that we pursue through institutions - may be set back by robust speech protection within those institutions. If this is right, then institutional contexts show us how robust speech freedoms can undermine the very moral development that they are meant to enable. For this reason, institutional contexts highlight the downsides of elevating sincerity above all other values in our regulation of speech. The upshot is that the legal protection of speech within institutions should be modulated in order to account for the potential conflicts between sincerity and other valuable ends, rather than being oriented above all to sincerity. Ultimately, when it comes 
to regulating speech, we cannot afford to treat sincerity as the first virtue of institutions.

\section{OPEN ACCESS}

This article is distributed under the terms of the Creative Commons Attribution 4.0 International License (http: / / creativecommons.org/licenses/by / 4.0/), which permits unrestricted use, distribution, and reproduction in any medium, provided you give appropriate credit to the original author(s) and the source, provide a link to the Creative Commons license, and indicate if changes were made.

Department of Philosophy,

University College London, Gower Street, London,

WC1E 6BT,

$U K$

E-mail: a.greene@ucl.ac.uk

Publisher's Note Springer Nature remains neutral with regard to jurisdictional claims in published maps and institutional affiliations. 